\section{Application of the Micro Biological Survey analytical method for the determination of bacterial load in cow raw milk}

\author{
Alessandra Cornacchia, ${ }^{1}$ Maria \\ Antonietta Saletti, ${ }^{1}$ Violeta Di Marzio, ${ }^{1}$ \\ Romolo Salini, ${ }^{1}$ Cristina Marfoglia, ${ }^{1}$ \\ Elga Tieri, ${ }^{1}$ Nicola D'Alterio, ${ }^{1}$ \\ Nicla Marri, ${ }^{2}$ Francesca Losito, ${ }^{3}$ \\ Alyexandra Arienzo, ${ }^{4}$ Lorenza Murgia, ${ }^{4}$ \\ Giovanni Antonini, ${ }^{3,4}$ Simonetta \\ Amatiste, ${ }^{2}$ Loris Leboffe, ${ }^{2,4}$ \\ Francesco Pomilio ${ }^{1}$ \\ ${ }^{1}$ Istituto Zooprofilattico Sperimentale \\ dell'Abruzzo e del Molise G. Caporale, \\ Teramo; ${ }^{2}$ Istituto Zooprofilattico \\ Sperimentale del Lazio e della Toscana \\ M. Aleandri, Rome; ${ }^{3}$ Istituto Nazionale \\ Biostrutture e Biosistemi - Consorzio \\ Interuniversitario, Rome; ${ }^{4}$ Dipartimento \\ di Scienze, Università degli Studi Roma \\ Tre, Rome Italy
}

\begin{abstract}
The aim of this study was to evaluate the performance of "Micro Biological Survey - MBS Test" in the enumeration of bacterial load in cow raw milk. The MBS test is based on a colorimetric method recently developed and patented by "Roma Tre" University, Italy. The evaluation of the performance of the MBS method was carried out by comparison with plate count at $30^{\circ} \mathrm{C}$ (gold standard) and flow cytometry. Thirteen independent set of experiments were performed analyzing a total of 104 samples of cow raw milk with the selected methods. Results obtained using the MBS method are comparable with those obtained with the plate count method at $30^{\circ} \mathrm{C}$ $(\mathrm{CFU} / \mathrm{mL})$ and flow cytometry technology; in particular, the results obtained with the MBS method are very close to plate count's at $30^{\circ} \mathrm{C}$. On the other hand, there are statistically significant differences between these two methods' and flow cytometry technology's results that could be due to the different experimental conditions
\end{abstract}

\section{Introduction}

The microbiological aspects of food safety have been studied intensively for many decades. A variety of tests are performed as part of standard bulk milk micro- biological quality assessment. Standardized methods (e.g. ISO methods) are acknowledged as reference analytical methods for official control and include plate count at $30^{\circ} \mathrm{C}$ (CFU/mL), widely used in food analysis laboratories, or faster and more advanced technologies, such as flow cytometry technology with Bactoscan FC Analyzer (Foss, Hilleroed, Denmark). With plate count at $30^{\circ} \mathrm{C}(\mathrm{CFU} / \mathrm{mL})$, long times and high expense are required to obtain results; on the contrary, flow cytometry requires short time and low expense, but, at the same time, expensive laboratory equipment and experienced operators. These reasons led to the development and further refinement of alternative microbiological methods of analysis, quicker and easier to perform, also allowing analysis within farms or by small food business operators.

The MBS method is a colorimetric, fast system for the detection and selective counting of bacteria in agro-food samples such as fresh dairy cheese (Losito et al., 2014) as well in water and in environmental samples (Traversetti et al., 2017). The MBS method measures the catalytic activity of redox enzymes of the main metabolic pathways of bacteria (Shultz and Chan, 2001; Slater, 2003; Antonini et al., 2007), allowing an unequivocal correlation between the observed enzymatic activity and the number of bacterial viable cells present in the samples. The time required for color change is inversely related to bacterial concentration; like an enzymatic reaction, the greater the number of bacteria, the faster the color change (Bottini G. et al, 2011, Losito F. et al., 2012).

The aim of this study was to provide evidence that the new MBS method (MBS "Roma Tre" University, Rome, Italy) could yield results which are equivalent to those provided by the corresponding reference or validated methods (Feinberg et al., 2009).

Milk samples were collected from local milk production holdings. The enumeration of the bacterial load using the plate count at $30^{\circ} \mathrm{C}(\mathrm{CFU} / \mathrm{mL})$, according to what is reported by Italian Ministerial Decree (March 26 ${ }^{\text {th }}, 1992$ ), concerning the establishment of methods of analysis related to raw milk and heat-treated milk, and the analysis using the MBS analytical kit were carried out at the "Food Hygiene Unit" at the Istituto Zooprofilattico dell'Abruzzo e del Molise "G.Caporale" (IZSAM) in Teramo, Italy. Subsample units were stabilized using sodium azide sticks (Sacco s.r.l, Cadorago, Italy) and sent to the IZSAM laboratory in Lanciano, Italy, to carry out the enumeration of bacteria with flow cytometry technology.
Correspondence: Alessandra Cornacchia, Batteriologia e Igiene delle produzioni lattiero-casearie, Istituto Zooprofilattico Sperimentale dell'Abruzzo e Molise "G. Caporale", Sede di Lanciano, 66034 Lanciano (CH), Italy. Tel: +390861332615

E-mail: a.cornacchia@izs.it

Key words: Cow raw milk, Plate count at $30^{\circ} \mathrm{C}(\mathrm{CFU} / \mathrm{mL})$, MBS test, Flow citometry, Bactoscan FC.

Contributions: The authors contributed equally.

Conflict of interests: The authors declare no potential conflict of interests.

Funding: This work has been partially supported by a Grant from Ministero della Salute of Italy to $l l$. Progetto ricerca finalizzata-giovani ricercatori 2011 (Development of a rapid, fast and low-cost analytical kit to evaluate quality and safety of milk and dairy products: GR2011-02348227)

Availability of data and materials: The data that support the findings of this study are available from the corresponding author upon reasonable request.

Ethics approval and consent to participate: This research was conducted in accordance with all relevant guidelines and procedures.

Consent for publication: The manuscript does not contain any individual person's data in any form.

Received for publication: 15 July 2018. Accepted for publication: 18 October 2019.

This work is licensed under a Creative Commons Attribution-NonCommercial 4.0 International License (CC BY-NC 4.0).

(C) Copyright: the Author(s), 2020

Licensee PAGEPress, Italy

Italian Journal of Food Safety 2020; 9:7696

doi:10.4081/ijfs.2020.7696

\section{Materials and Methods}

\section{Sample preparation}

Thirteen independent sets of experiments were performed analyzing a total of 104 samples of cow raw milk with the methods under investigation. The milk was first homogenized by stirring on a magnetic plate (Cenco Italia spa, Milano, Italy) for $10 \mathrm{~min}$ utes. After homogenization from the container, four milk sampling units were taken, placed in sterile containers (Electron-Nord, Borre, France). Two further sub-samples were obtained from each container, in order to obtain 8 laboratory samples for each day 
of analysis. During the analysis, samples were kept at $4 \pm 2^{\circ} \mathrm{C}$ or in melting ice.

\section{Plate count at $30^{\circ} \mathrm{C}(\mathrm{CFU} / \mathrm{mL})$}

Before the test was performed, the solid medium for the enumeration of mesophilic bacteria in milk, namely PCA-L (Biolife Italiana srl, Monza, Italy), was sterilized in autoclave at $121 \pm 1{ }^{\circ} \mathrm{C}$ for 15 minutes and allowed to cool in water bath at $45 \pm 1{ }^{\circ} \mathrm{C}$. Each laboratory sample of milk was carefully mixed, to obtain a distribution of the microorganisms in the tested portion as uniform as possible, by rapidly and repeatedly inverting the sample content. In order to reduce the number of microorganisms per unit volume, further decimal dilutions of the sample were prepared, and dilutions were pour plated by transferring $1 \mathrm{~mL}$ of the sample (initial suspension and/or decimal dilution) into sterile Petri dishes. Subsequently, 15-18 mL of dissolved agar (PCA-L) were poured into each plate and the sample was evenly distributed by rotating the plates. Once allowed the medium to solidify, plates were incubated at $30 \pm 1^{\circ} \mathrm{C}$ for $72 \pm 2 \mathrm{~h}$. After incubation, colony count was done manually.

\section{MBS Test}

The analytical procedure for the quantitative colorimetric MBS method is based on a colorimetric assay, using a redox indicator of the change of the oxido-reductive state in the reaction medium. For the analysis by the MBS method, ready-to-use MBS vials, sterilized and containing the reagent for the analysis, were used. To carry out the analysis, $10 \mathrm{~mL}$ of sterile deionized water and 1 $\mathrm{mL}$ of milk sample were added to a vial. The vial was shaken until the reagent was completely dissolved. Later, the vial was placed in the MBS-MR device and incubated at $30^{\circ} \mathrm{C}$. The MBS-MR device (Figure 1) was connected to a computer that had been programmed for each day of analysis by entering data about the sample (NRG, date, operator, matrix, method, quantity of sample inserted into the tube) and where results were analyzed. The starting color of vials was blue, and in the presence of microorganisms the color of the vials changed to yellow in few hours, indicating a positive result (Figure 2). The time for the yellow color development is inversely related to the number of bacteria into the analyzed sample. The persistence of the starting color after $24 \mathrm{~h}$ indicates a negative result, i.e., below level of detection of the method (Bottini G., et al., 2011).

The relation adopted for the calculation of the $\mathrm{CFU} / \mathrm{mL}$ values estimated by the MBS method is given by the following equation:

$\log \mathrm{CFU} / \mathrm{mL}=-0,3134 *$ time $\mathrm{MBS}+8,4307$
Time MBS: Time taken for vials to change color (from blue to yellow).

\section{Flow cytometry technology}

The flow cytometry technology was performed using Automated BactoScan ${ }^{\mathrm{TM}}$ FC analyzer, which gives a uniform high accuracy of results counting single cells and reducing bias due to cells clusters. It is based on flow cytometry technology that enables precise and instant milk bacteria analyses. In flow cytometry a suspension of cells is stained and forced through a capillary tube, which is illuminated in front of microscope objective lenses. Every passing cell is registered by photo electronics attached to the microscope. A syringe is used to pass the sample through a flow cell, presenting the bacteria one by one to a fluorescent light beam from a laser source. The stained bacteria emit red light with one light pulse for every cell passing the beam. The fluorescent light is detected by a highly sen- sitive detector (Photo Multiplier Tube PMT), which gives electronic impulses. BactoScan $^{\mathrm{TM}}$ FC measures Individual Bacteria Count and displays results in IBC. Consequently, a national conversion table has been created to convert from IBC to CFU. The repeatability and reproducibility of this automated method was excellent compared to plate count at $30^{\circ} \mathrm{C}(\mathrm{CFU} / \mathrm{mL}$.

The results expressed by flow cytometry technology as $\mathrm{IBC} / \mathrm{mL}$ were converted to $\mathrm{CFU} / \mathrm{mL}$ according to a statistical relationship existing between IBC and CFU described by the following equation: $\log ($ UFC $)=\log ($ IBC $) * 0.9172-0.2021$.

The equation has been calculated with reference to the report of the "National conversion project flow cytometry" (2012).

Once the equations have been applied to all samples it was possible to put the three methods in statistical correlation and graphically represent the results obtained with the methods under investigation.

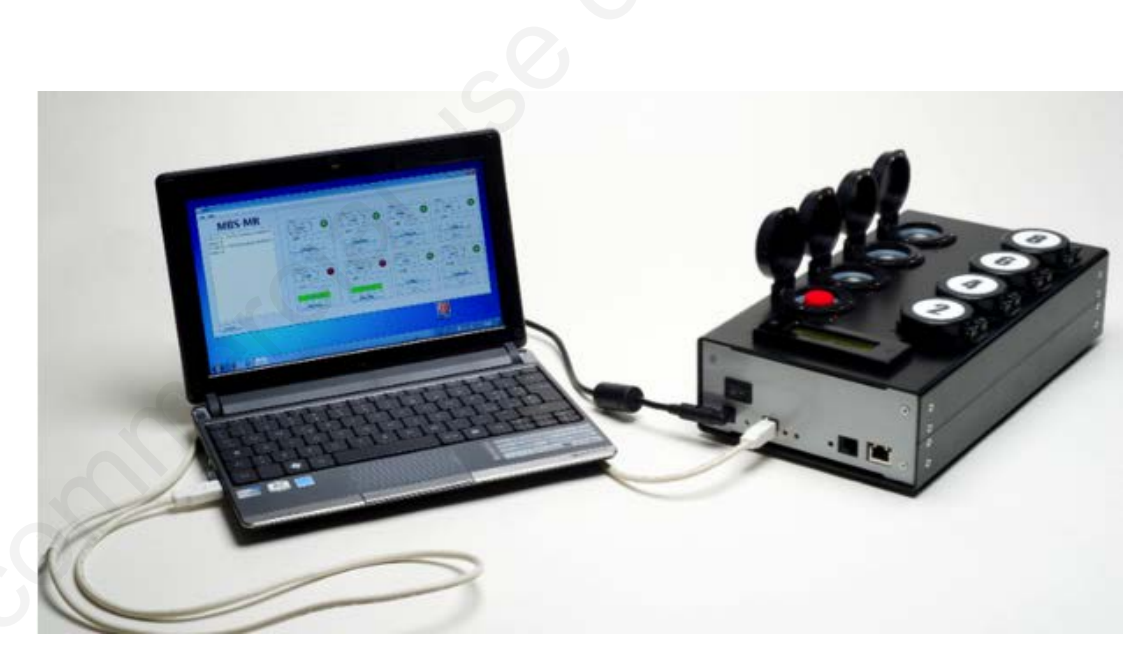

Figure 1. MBS-MR device connected to a computer that is programmed for each day of analysis (Picture from MBS srl).

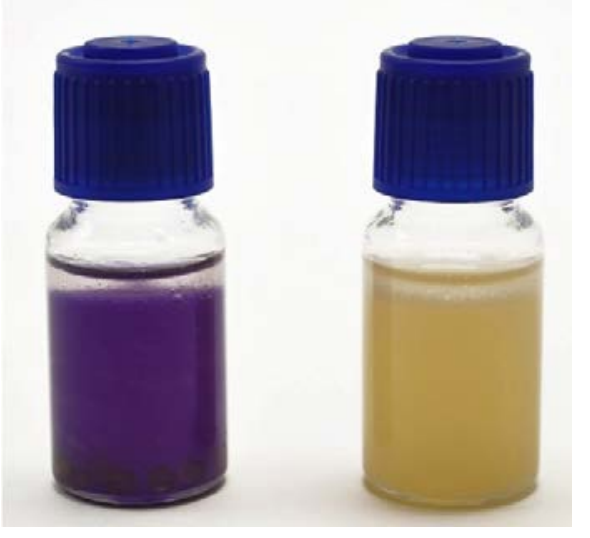

Figure 2. Starting colors blue vialsthat in the presence of microorganisms changes to yellow color indicating a positive result (Picture from MBS srl). 


\section{Statistical analysis}

A non-parametric Friedman test (for $\mathrm{k}$ paired samples) was applied to verify the differences between the results obtained with the three methods. Comparisons have also been carried out in pairs a posteriori, using the Nemenyi test, with Bonferroni correction. Table 1 shows the values of pairwise comparisons (significant comparisons in bold).

\section{Results}

The results of the analyses carried out were reported in Figure 3. Based on the experimental results, the regression line correlating the decimal logarithms of the plate count at $30^{\circ} \mathrm{C}(\mathrm{CFU} / \mathrm{mL})$ and the times for color change of vials, in terms of hours, obtained through the MBS method, has been determined (Figure 4).

As can be seen in Figure 4, this analysis yielded a coefficient of determination (R2) equal to 0.6618 .

Furthermore, a non-parametric Friedman test (for $\mathrm{k}$ paired samples) was applied to verify the differences between the analytical results of the three methods compared. The Friedmann test (Table 1) showed statistically significant differences with a p-value $<0.0001$ between Bactoscan FC and the other two methods. Comparisons have also been carried out in pairs a posteriori, using the Nemenyi test, with Bonferroni correction. The results obtained using the MBS method are comparable with those obtained with the plate count at $30^{\circ} \mathrm{C}(\mathrm{CFU} / \mathrm{mL})$ reference method.

\section{Discussion and Conclusions}

In recent years, the need to rapidly assess the microbiological quality of raw materials and finished products has led to the development and further refinement of alternative microbiological methods of analysis. Such alternative methods are quicker and easier to perform than the corresponding reference method (Feinberg et al., 2009). In this context, the aim of the present study was to compare the results obtained with MBS method, and the results obtained with the reference method (plate count at $30^{\circ} \mathrm{C}$ ) and the flow cytometry technology.

The results reported in this study further support the previous findings concerning the existence of a stringent correlation between metabolic activity of bacteria and the number of viable cells.

The results were statistically analyzed and compared verifying a concordance between the plate count at $30^{\circ} \mathrm{C}(\mathrm{CFU} / \mathrm{mL})$ and the MBS method for the enumeration of bacteria in cow raw milk samples; at the same time, the statistical analysis provided evidence of some differences between these two methods and flow cytometry technology. This variability could be the consequence of the use of sodium azide sticks (used to ensure effective conservation of the samples that were sent to the Lanciano laboratory Unit for the flow cytometry analysis), different storage conditions and increased storage time; some tests were also carried out on different days.

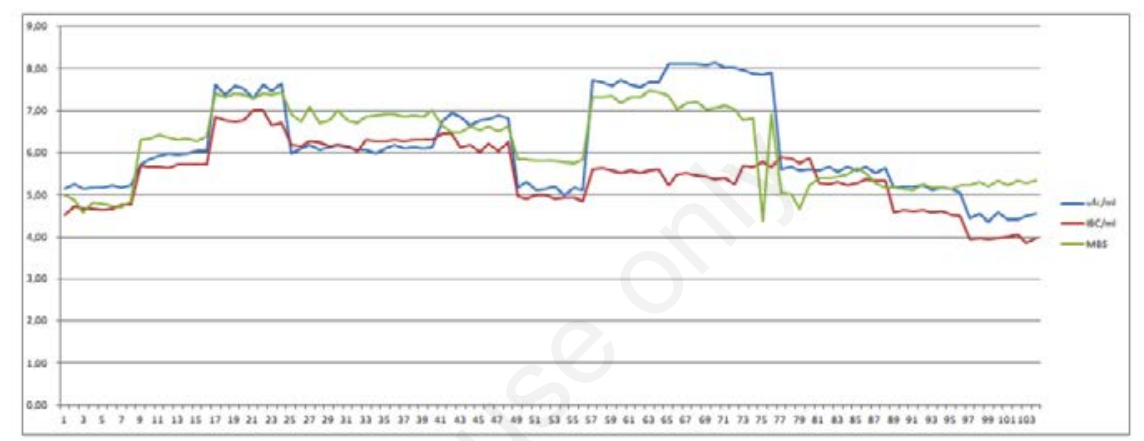

Figure 3. Graphical representation of the trend of the three methods: in blue the plate count at $30^{\circ} \mathrm{C}(\mathrm{CFU} / \mathrm{mL})$, in green the MBS test, in red flow cytometry technology with Bactoscan FC.

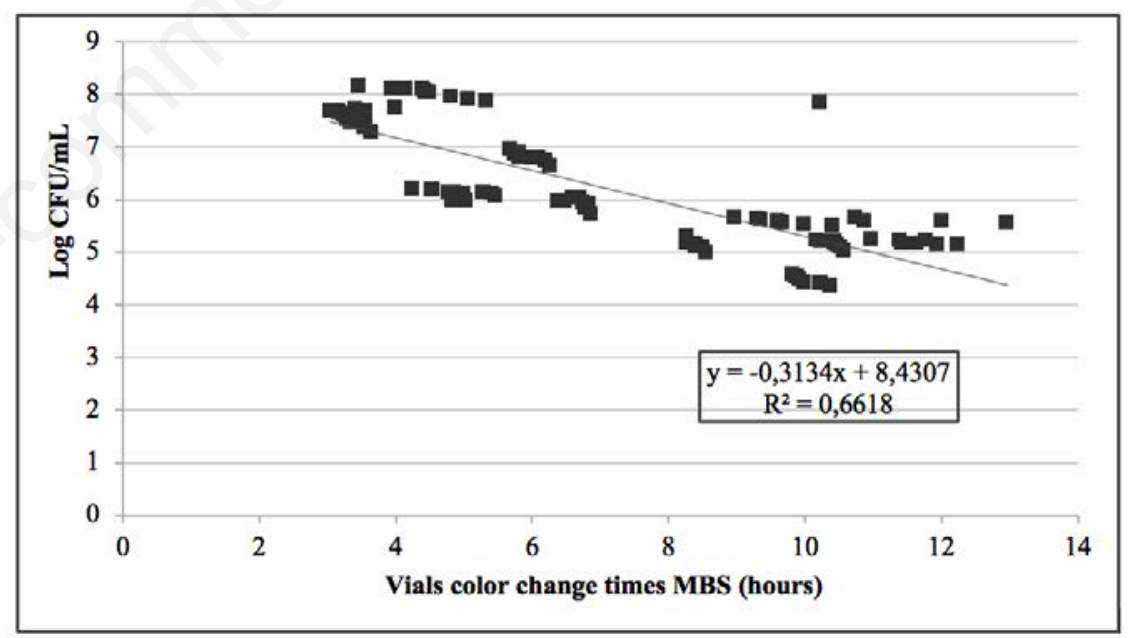

Figure 4. Regression of the decimal logarithms of the Total Bacterial Load in plate in relation to the turning times of the MBS method.

Table 1. Values of pairwise comparison.

\begin{tabular}{lccc} 
& Plate count at $30^{\circ} \mathrm{C}^{*}$ & Flow cytometry** & MIBS \\
Plate count at $30^{\circ} \mathrm{C}^{*}$ & 1 & $<0.0001$ & 0.782 \\
Flow cytometry** & $<0.0001$ & 1 & $<0.0001$ \\
\hline MBS & 0.782 & $<0.0001$ & 0 \\
\hline
\end{tabular}

${ }^{*} \log 10(\mathrm{CFU} / \mathrm{mL}),{ }^{* *} \log 10(\mathrm{IBC} / \mathrm{mL})$
Comparing the MBS method to plate count method at $30^{\circ} \mathrm{C} \mathrm{CFU} / \mathrm{mL}$ ), the following considerations come to light. With traditional plate count at $30^{\circ} \mathrm{C}(\mathrm{CFU} / \mathrm{mL})$ bacteria replication can be observed with naked eye but greater expertise in the exact quantification of the number of bacteria over a large range of concentrations is expensive and time-consuming. On the other hand, flow cytometry technology often turned out to be very expensive, also requiring highly equipped laboratories. Colorimetric methods currently available 
are mainly based upon measure of microorganisms' secondary metabolism (Balouiri et al., 2016), they are very quick and sensitivity can be improved by using automated o semi-automated systems.

The comparison here reported provided evidence that the MBS method for total viable count in cow raw milk samples gives similar results and is in agreement with the plate count at $30^{\circ} \mathrm{C}(\mathrm{CFU} / \mathrm{mL})$ and flow cytometry methods, also confirming reproducibility, specificity and selectivity of the MBS method. The MBS method could therefore become a valid support for the control of raw milk in production holdings; its characteristics of reproducibility, accuracy, economy and portability make it particularly suitable for own-check by small and medium holdings or establishments for milk and dairy production, helping to ensure the monitoring of both quality and safety along the entire food chain even in the absence of laboratories. Some differences reported for tested samples highlight the need to test more samples in the same Laboratory Unit and in the same analytical conditions to decrease possible bias and to obtain more robust data.

\section{References}

Antonini G, Malatesta F, Sarti P, 2007. Twenty-five years of cytochrome oxidase research in Rome with Maurizio Brunori. IUBMB Life 59:5707.

Balouiri M, Sadiki M, Ibnsouda SK, 2016. Methods for in vitro evaluating antimicrobial activity: A review. J Pharmaceut Anal 6:71-9.

Bottini G, Losito F, De Ascenti A, Priolisi FR, Mari A, Antonini G, 2011. Validation of the Micro Biological Survey Method for Total Viable Count and E. coli in Food Samples. Am J Food Technol, 6:951-62.

Feinberg M, Sohier D, David JF, 2009. Validation of an alternative method for counting Enterobacteriaceae in foods based on accuracy profile. J AOAC Int 2:527-37.

Italian Ministerial Decree March 26, 1992. Implementation of decision n. 91/180 / EEC concerning the establishment of methods of analysis and testing relating to raw milk and heat-treated milk. (GU General Series No. 90 of 16-04-1992 Ordinary Supplement No. 67).

IZS Lombardia ed Emilia-Romagna (IZSLER), 2013. Aggiornamento dell'equazione di conversione per la deter- minazione della carica batterica nel latte tramite apparecchiature automatiche operanti in citometria di flusso "produzione e validazione della conversione nazionale Bactoscan FC - anno 2012”. Report rev. 3 - 6 giugno 2013.

Losito F, Bottini G, De Ascentis A, Priolisi FR, Mari A, Tarsitani G, Antonini G, 2012. Qualitative and Quantitative Validation of the Micro Biological Survey Method for Listeria spp., Salmonella spp., Enterobacteriaceae and Staphylococcus aureus in Food Samples. Am J Food Technol 7:340-51.

Losito F, Arienzo A, Bottini G, Priolisi FR, Mari A, Antonini G, 2014. Microbiological safety and quality of Mozzarella cheese assessed by the microbiological survey method. J Dairy Sci 97:46-55.

Shultz BE, Chan SI, 2001. Structures and proton-pumping strategies of mitochondrial respiratory enzymes. Annu Rev Biophys Biomol Struct 30:23-65.

Slater EC, 2003. Keilin, cytochrome and the respiratory chain. J Biol Chem 278: 16455-61.

Traversetti L, Losito F, Arienzo A, Stalio O, Antonini G, Scalici M, 2017. Integrating running water monitoring tools with the Micro Biological Survey (MBS) method to improve water quality assessment. PLoS ONE, 12:e185156. 